\title{
Neo-Eurasianismo, geopolítica e a política externa dos EUA à URSS durante a guerra fria
}

\section{Neo-Eurasianism geopolitics and the United States external policy for the Soviet Union during the cold war}

\section{SERGIO ROBERTO GOUVÊA LOPES BEATRIZ MARCONDES AZEVEDO FRED LEITE SIQUEIRA CAMPOS}

\section{INTRODUÇÃO}

As teorias de geopolítica, aqui estudadas, foram formuladas por acadêmicos e militares da Inglaterra e dos Estados Unidos (EUA), durante os séculos XIX e XX, que se autodenominavam "potências marítimas", tendo como adversários, as chamadas "potências terrestres". Tais conceitos foram trabalhados por geógrafos, políticos e militares de diversos países, tendo como principais escolas a já mencionada anglo-saxã, mas também a alemã e a francesa. ${ }^{1}$

Por outro lado, os principais formuladores da política externa dos EUA, durante os últimos anos da Segunda Guerra Mundial e, posteriormente, na Guerra Fria, estipularam diretrizes gerais e específicas para a ação do seu país no cenário do pós-Guerra. Dentre esses cenários, o principal, em torno do qual giravam todos os demais dizia respeito à União Soviética (URSS). Além disso, convencionou-se entre os estudiosos do tema denominar de "estratégia de contenção" o conjunto de políticas e ações levadas a cabo pelos EUA contra a potência socialista. Esse agregado de políticas seria guiado principalmente pelo artigo "The Sources of Soviet Conduct", escrito pelo diplomata estadunidense George Kennan, em 1947 e pelo documento "NSC-68" redigido pelo Conselho de Segurança Nacional dos Estados Unidos, em 1950.

Sergio Roberto Gouvêa Lopes - Universidade Federal de Santa Catarina.

Beatriz Marcondes Azevedo - Universidade Federal de Santa Catarina.

Fred Leite Siqueira Campos - Universidade Federal de Santa Catarina. 
Com o fim da Guerra Fria e da bipolaridade no sistema internacional, esse conjunto de estratégias e políticas teve continuidade e, apesar da mudança de cenário, sua lógica essencial parece não ter mudado. As disposições táticas e as diretrizes de política externa dos EUA para a Europa Oriental e países da extinta URSS possuem traços semelhantes àqueles da antiga "estratégia de contenção", dessa vez tendo como alvo a Federação Russa. Apesar da mudança sistêmica, a política externa dos EUA naquela região demonstra profunda semelhança com as teorizações geopolíticas do período anterior (Dugin, 2014).

Tal narrativa é defendida, sobretudo, pela contemporânea teoria geopolítica russa do "Neo-Eurasianismo" e, em especial, nos escritos de seu mais proeminente teórico, Alexander Dugin. A ideia de se propor uma análise das semelhanças entre as teorias geopolíticas anglo-saxãs e a política externa norte-americana durante a Guerra Fria à luz da teoria geopolítica russa está assentada no pressuposto de que existe uma grande proeminência na atual Federação Russa, primordialmente nas estratégias da política externa daquele país (Clover, 2016).

Diante do exposto, tem-se como objetivo deste trabalho, analisar os padrões de comportamento entre as teorias geopolíticas formuladas por intelectuais anglo-saxônicos e os documentos da política externa concreta dos EUA para a URSS desde o fim da Segunda Guerra Mundial até o fim da Guerra Fria.

A justificativa deste trabalho encontra-se relacionada à premissa de que, apesar da geopolítica ter sido por muito tempo sido estigmatizada dentro e fora da academia como "ciência nazista" ou "militarista", desde o fim da Guerra Fria ela vem retomando espaço e sendo foco de grande atenção nos mais variados países (Costa, 2010).

Em outras palavras, enfatiza-se o entendimento de que a geopolítica insiste em crescer e tomar espaço, principalmente no centro hegemônico (EUA). Isso tem sido demonstrado pelas diversas intervenções militares levadas a cabo por aquele país nas últimas duas décadas, bem como pelo ressurgimento da Rússia como potência regional e da China como grande concorrente à hegemonia norte-americana (Albuquerque, 2010).

Ao contrário do que muitos haviam apostado ao fim da Guerra Fria e diante do Colapso da URSS, a humanidade parece não ter atingido o "Fim da História” previsto por Fukuyama (1992). A própria Federação Russa, após uma década de caos e tormenta, retomou seu crescimento e fez lembrar ao mundo que a URSS não havia sido militarmente derrotada e que, como sua sucessora, ainda dispunha de poderosas Forças Armadas. Neste contexto, a Rússia reaqueceu sua economia com os recursos provindos da exploração dos combustíveis fósseis, principal motivo de conflitos geopo- 
líticos nas duas últimas décadas e voltou ao Big Game pelo controle do heartland (Bandeira, 2009).

Devido a todos esses pontos, parece fazer-se urgente o retorno ao estudo da geopolítica em geral e dos seus desdobramentos nas relações EUA-Rússia em particular. A análise das políticas norte-americanas em relação à extinta União Soviética aparenta ser de significativa utilidade para que se entendam as relações internacionais contemporâneas.

No que diz respeito aos aspectos metodológicos, o presente trabalho se caracteriza como pesquisa documental e bibliográfica. Dentro desses parâmetros, primeiramente tem-se uma revisão de literatura das principais teorias de geopolítica anglo-saxãs e dos principais documentos de política externa dos EUA durante a Guerra Fria. Com base na coleta dos referidos dados, buscou-se traçar os possíveis paralelos encontrados entre as teorias de geopolítica e os documentos de política externa, bem como analisar as semelhanças encontradas à luz da teoria do "Neo-Eurasianismo".

\section{AS TEORIAS GEOPOLÍTICAS ANGLO-SAXÔNICAS}

Segundo Dugin (2013), apesar do termo "geopolítica” ter sido inicialmente cunhado por Rudolf Kjellen (1864-1922), e por ele traçados os primeiros entendimentos acerca dessa matéria, foi Sir Halford Mackinder quem lançou as bases essenciais deste campo, usadas por todos teóricos posteriores. Nesta linha de raciocínio, Costa (2010) atribuiu a Friedrich Ratzel (1844-1904) e a Camille Vallaux (1870-1945) o papel de cofundadores da geopolítica, mediante seus trabalhos em Geografia Política.

Em relação à conceituação do termo, é possível perceber sutis diferenças de entendimento entre três autores de diferentes países: Wanderley Messias da Costa, brasileiro; Nicholas Spykman, americano; e Alexander Dugin, russo. Tal fato é decorrente da própria natureza da Geopolítica em estudar a relação entre espaço geográfico e sua influência na política. Portanto, parece razoável existir uma mudança discursiva entre autores de nacionalidades distintas.

Costa, em seu manual de 2010, Geografia Política e Geopolítica, sugere que, para que se estude as teorias de geopolítica, é necessário aceitar alguns pressupostos de que existem, de fato, relações entre os processos sociais e os espaços nos quais eles ocorrem. Segundo este autor, para que isso aconteça, é necessário aceitar que todas as sociedades humanas organizadas com fins políticos, comunitários e produtivos, exercem alguma relação com o espaço geográfico, não restringindo essas relações ao nível do Estado Moderno. 
Spykman, em seu artigo Geography and Foreign Policy, de 1938, aborda o tema de maneira sutilmente distinta, dando maior ênfase à esfera Estatal da geopolítica. $\mathrm{O}$ autor defende a influência do posicionamento geográfico dos países em sua política externa, partindo do princípio de que a geografia é a mais constante variável na equação de poder de um Estado e que, é a partir daquela realidade territorial que o mesmo irá operar nos tempos de guerra, ou se estruturar, nos tempos de paz. Nessa perspectiva, Spykman (1938) afirma que as realidades geográficas às quais está relegado um Estado são relativamente estáveis e imutáveis, além de que as demandas geográficas desses Estados se manterão as mesmas por séculos. Desse modo, a geopolítica seria o fator fundamental que condicionaria as políticas dos Estados no sistema internacional.

Finalmente, Dugin (2014) define geopolítica em termos semelhantes com os outros dois. Tanto em seu ensaio "A Grande Guerra dos Continentes”, de 1992, quanto em "A Geopolítica da Rússia Contemporânea”, ele argumenta favoravelmente à ideia de que a geopolítica é a análise das realidades quase imutáveis entre uma dada população socialmente organizada e seu entorno geográfico. A grande diferença entre esse teórico e os seus congêneres do Brasil e dos EUA, é que Dugin propõe que, não apenas existe essa relação, como que ela é um dos fatores que definem o "ethos" da civilização situada naquela região geográfica. Haveriam, então, dois tipos de civilizações, as "terrestres" ou "telurocráticas" e as "marítimas" ou "talassocráticas".

No que diz respeito aos objetivos da geopolítica, de acordo com as teorizações dos três autores mencionados, pode-se citar o estudo das relações entre as organizações sociais e seu entorno geográfico, bem como maximizar o poder do Estado ao qual ela pertence.

\section{A POLÍTICA EXTERNA DOS ESTADOS UNIDOS NA GUERRA FRIA}

Para discorrer acerca da política externa dos EUA na Guerra Fria, optou-se por discutir o documento que talvez seja o mais famoso dentre os pareceres oficiais norte-americanos do começo da Guerra Fria: $A$ Report to the National Security Council - NSC 68, ou apenas NSC 68. Esse documento foi inspirado pelo artigo do diplomata norte-americano de longa experiência com a URSS, George Kennan, The Sources of Soviet Conduct.

Também foram discutidos escritos que não podem classificados como “documentos oficiais” da Política Externa estadunidense, mas que, por serem de autoria de duas das mais influentes figuras em dita política naquele período, nomeadamente, Henry Kissinger e Zbigniew Brzezinski, foram considerados relevantes para entender a relação entre os EUA e a URSS. Especificamente, da parte de Kissinger, analisa-se sua obra autobiográfica, 
White House Years: 1968-1972, enquanto que da parte de Brzezisnki, o foco centra-se nos conteúdos dos livros The Grand Chessboard: America's Primacy and Its Geoestrategic Imperatives (escrito depois da Guerra Fria) e Between Two Ages: America's Role in the Technetronic Era, escrito naquele período.

No início da Guerra Fria, os EUA buscavam compreender a natureza da ameaça soviética e, para tal, o chamado NSC 68 foi um dos primeiros e mais importantes instrumentos na missão de esclarecer os tomadores de decisão norte-americanos sobre essa questão (Wells, 1979).

$\mathrm{O}$ documento começa com uma breve reflexão sobre o período anterior àquele no qual era escrito. Na sequência, faz-se uma distinção entre o propósito precípuo dos EUA e a configuração fundamental do Kremlin. Neste sentido, diz-se que o objetivo essencial da potência norte-americana é descrito como o de assegurar a segurança e vitalidade da "sociedade livre" e da dignidade do indivíduo. Além disso, defende-se a ideia de que aquele país está determinado a defender as liberdades individuais, criar as condições para que floresça o sistema democrático e, se necessário, lutar para defender esse estilo de vida.

No Kremlin, por sua vez, o ímpeto fundamental seria o de manter e solidificar o poder daqueles que controlam a URSS e o movimento comunista internacional, sendo necessário alargar sua influência e neutralizar quaisquer oposições à sua autoridade. A tática para atingir esses objetivos seria a subversão e posterior destruição dos governos e sociedades do mundo não soviético e a sua substituição por instituições títeres de Moscou. Para tal fim, o documento revela que os esforços soviéticos eram direcionados para a dominação da massa continental eurasiana. Os EUA, por outro lado, seriam considerados pelo Kremlin, como seu principal inimigo na consecução desse plano e, por isso, deveriam ser subvertidos ou destruídos, empregando quaisquer meios necessários.

Sendo assim, se a luta se delineava nesses parâmetros, caberia então aos EUA se colocarem na posição de liderança mundial, ajudando outros povos do "mundo livre" no desenvolvimento de capacidade militar e moral para que seja resguardada a segurança nacional norte-americana e para que a URSS tomasse conhecimento da falsidade de suas crenças e se acomodasse ao sistema internacional, convivendo de forma pacífica com os demais países e abandonando os seus desígnios. O documento revela ainda que a política externa norte-americana não objetivava a subjugação do povo russo, o que poderia fazê-lo apoiar ainda mais o "governo que os oprimia", mas auxiliá-lo a conseguir uma nova chance de seguir rumos diferentes na sua comunidade nacional.

Ao pautar-se ainda em uma outra linha argumentativa, o documento explicita que apenas o conflito militar e a vitória em dito conflito não 
seria suficiente, já que, tratando-se de uma guerra também psicológica e ideológica, a destruição física da URSS não impediria o ressurgimento de outro regime totalitário. Sendo assim, a menos que se conseguisse incutir na mente das pessoas a ideia básica de liberdade, o substrato essencial do conflito, não tardaria em surgir outro sistema incumbido de levar a cabo o desígnio soviético.

Baseando-se nesse cenário de conflito e seus motivos, a política externa dos EUA tinha como objetivos: desenvolver um sistema internacional saudável baseado nas organizações internacionais propostas no pós-Guerra; impedir a expansão daquele país; expor as falsidades das pretensões soviéticas; induzir a retração do controle e influência do Kremlin; e plantar as sementes da implosão do sistema soviético. Além disso, seria necessário manter e alargar a já existente superioridade de poder por parte dos Estados Unidos, destacadamente, no campo militar.

Ao prosseguir na estratégia delineada para os EUA, o documento propõe o fortalecimento econômico e defensivo da Europa Ocidental e, sobretudo, da Grã-Bretanha. Assim, seria de suma importância que os aliados ou potenciais aliados dos americanos não caíssem em condições de neutralidade, o que potencializaria o perigo do domínio soviético. Entende-se que se isso viesse a acontecer com a Alemanha, as consequências para a Europa e, posteriormente para os EUA, seriam catastróficas. Em relação à Ásia, seria recomendado o fortalecimento dos governos moderados daquele continente, também o fortalecimento social, das instituições e economias para que os recursos materiais e humanos daquela região pudessem ser melhor utilizados.

$\mathrm{O}$ artigo The Sources of Soviet Conduct, publicado pelo diplomata George Kennan, sob o codinome "X", na revista Foreign Affairs, em 1947, serviu como base para a elaboração do documento NSC 68. Kennan (1947) desenvolveu a ideia de que a Guerra Fria seria a oportunidade para os EUA assumirem a liderança do chamado "mundo livre".

Neste sentido, Kennan (1947) inicia seu artigo fazendo uma breve análise do pensamento do homem soviético e da estrutura de sua sociedade, de suas raízes na revolução e no pensamento leninista. Tem-se assim a configuração stalinista da sociedade, na qual, sob os auspícios do ditador, se mantinham os “órgãos de supressão". Segundo ele, tais medidas brotavam do entendimento das elites de que, enquanto houvesse um cercamento capitalista ao Estado Soviético, haveria perigo de invasão. Desse sentimento surgia também a percepção de que todas as forças de oposição dentro da potência socialista seriam agentes reacionários estrangeiros controlados para desestruturar o Estado Soviético.

O sentimento de insegurança e a ideologia universalista do marxismo se combinavam num ímpeto de revolução global. Apesar disso, o autor 
afirma que os dirigentes soviéticos não se apressavam em cumprir essa missão e se portavam de maneira bastante realista frente às suas potencialidades. Para Kennan (1947), essa serenidade para a realização dos seus objetivos era herança das lições aprendidas durante séculos pela Rússia, que enfrentara as idas e vindas das invasões nômades pelas extensas planícies. Para suportar tais intempéries da história, o cuidado, a circunspecção, a flexibilidade e furtividade foram consideradas suas principais qualidades. Em consequência disso, a URSS teria herdado essas características na sua missão revolucionária. Como resposta, os EUA não deveriam, em nenhum momento, aliviar a pressão sobre o sistema soviético, e que sua conduta deveria impor às ações da potência socialista um considerável grau de moderação, muito maior aos observados nos anos anteriores.

A obra de Henry Kissinger, denominada, White House Years: 1968-1972, é reconhecida pela significativa importância do autor nos estudos sobre a Guerra Fria. Kissinger (2011) afirma no início de sua obra que, uma vez que havia assumido o cargo de Conselheiro de Segurança Nacional daquele governo, foi a ele dada a missão de restabelecer o National Security Council, composto por representantes de todas as agências governamentais relevantes.

Ao avançar em sua análise, o autor afirma que, apesar do isolacionismo, o Almirante Mahan demonstrou que os EUA poderiam pensar de maneira geopolítica. Segundo o mesmo, a potência norte-americana chegou ao século XX sem ter aprendido essa lição. Apesar disso, argumenta-se que a entrada dos EUA na Primeira Guerra Mundial havia sido consequência direta do interesse geopolítico americano em manter a liberdade de navegação e prevenir que a Europa fosse dominada por poderes hostis. No entanto, Kissinger (2011) pressupunha que a política subsequente foi baseada em termos legalistas e idealistas. Protegido por dois oceanos, aquele país não pensava de maneira estratégica e mesmo seus esforços militares eram mais focados em logística do que geopolítica.

Kissinger (2011) assinala que a estratégia de contenção do imediato pós-guerra foi falha e presenteou à União Soviética o tempo necessário para reorganizar suas forças. Em seu argumento, a falha se deu, primeiramente, pela crença excessiva dos EUA na eficácia do balanço de poder europeu; em segundo lugar, pela falta de percepção de que as armas nucleares davam aos EUA uma grande vantagem em relação aos soviéticos e, em terceiro lugar, pela incapacidade de entender que a mera contenção não poderia combater efetivamente a ideologia comunista, que transformava a luta entre países em uma luta entre filosofias e modos de vida, inclusive de forma interna aos países ocidentais. 
Os EUA não estavam preparados para enfrentar um adversário tão forte, durante tanto tempo e tão radicalmente hostil a ele quando do fim da Segunda Guerra Mundial. Kissinger (2011) considera digno de nota que se tenha cogitado voltar à tradicional postura isolacionista depois da Guerra, sendo que países tradicionais na balança de poder, como Japão, Alemanha e China estavam completamente destruídos e a Grã-Bretanha já não tinha condições de ser o fiel da balança. Segundo ele, os EUA, de alguma forma, celebraram o vácuo de poder e acreditaram que, com ele, poderiam resolver todos os problemas de maneira diplomática e no âmbito das Nações Unidas.

Ao passar para uma análise das motivações e natureza da política externa da URSS, o autor salienta que a principal característica a se considerar era a crença de sua elite no comunismo. Desse modo, enquanto que a paz, para o Ocidente, seria o estado natural, a ausência de desavenças e a preponderância da harmonia, para o Oriente comunista a paz só aconteceria com a vitória de um dos lados.

Kissinger (2011) considerava complicado lidar com a URSS, dado que sua política externa obscureceu as linhas entre o que era propriamente interestatal e intraestatal. Se no cenário clássico da política internacional a interferência de um Estado sobre outro geralmente se dava na forma de agressão territorial, naquele momento, a URSS influenciava a política externa de outros povos como ferramenta de sua política internacional. Sendo assim, a ideologia colocava em cheque a estabilidade internacional e se tornava crescentemente perigosa devido ao fato de não aceitar conciliação.

O mesmo autor ressalta, no entanto, que a política soviética nada mais era do que a herdeira da antiga tradição do nacionalismo russo. Segundo ele, há séculos, desde o Ducado Moscovita, o Império Russo havia se expandido a leste e oeste, por meio das planícies infinitas sem conhecer obstáculos geográficos. Ainda, da mesma forma que os russos haviam ocupado as grandes planícies, também agressores contra aquele país havia se usado desse artifício, sempre sem sucesso. No entanto, as seguidas agressões infundiram no povo russo a equalização da segurança com a expansão territorial contínua o que, ao mesmo tempo, sempre gerou a máxima insegurança em seus vizinhos. $\mathrm{O}$ autor conclui esse argumento dizendo que, seja por um sentimento de insegurança ou por um sentimento de inferioridade, os governantes russos, comunistas ou czaristas, sempre identificaram a segurança não apenas com o espaço, mas com a dominação sobre outros povos. Portanto, concentrar-se em quais seriam os objetivos específicos da política externa soviética seria um erro, já que essa combinação de nacionalismo e ideologia seria a motivação essencial de cada movimentação geopolítica da URSS. 
Ao focar a questão nuclear e o Mutually Assured Destruction - MAD (Destruição Mutuamente Assegurada), Kissinger (2011) dizia que no fim dos anos 1960, mesmo diante do crescente poderio da URSS, da ideologia comunista, do expansionismo russo e do intervencionismo soviético, nenhum líder poderia deixar de contemplar a magnitude da ameaça das bombas atômicas, sendo que ambos países já possuíam armas suficientes para destruir a humanidade. A missão de afastar o perigo da confrontação nuclear se mostrava especialmente delicada, já que o discurso pacifista poderia obscurecer o que era um desafio ideológico e geopolítico que se prolongaria por gerações. Apesar disso, inúmeros esforços foram tomados para o "relaxamento" das tensões, sobretudo na Europa oriental.

A estratégia daquele período para com a China comunista não era considerada inerentemente antissoviética, mas buscava um equilíbrio global de poder. Sendo assim, os EUA decidiram não limitar seu contato com o mundo comunista à URSS. Ao fim dos anos 1960, praticamente todas suas relações com os países do bloco socialista eram trilaterais, envolvendo os EUA, a URSS e dado país. Tais relações poderiam possibilitar um equilíbrio entre as superpotências e até uma eventual cooperação. Em seus cálculos, as disputas fronteiriças entre China e União Soviética, para além da animosidade ideológica e histórica, ajudariam a aproximação dos EUA com o país asiático.

Em relação ao Japão, Kissinger (2011) afirma ser uma aliança entre aquele país e os EUA a peça chave da política externa norte-americana no pacífico. O governo americano tinha como principais objetivos naquela nação asiática a reorganização da balança comercial entre os dois países, que era crescentemente desfavorável para os EUA e também a tentativa de que o Japão assumisse maiores responsabilidades pelo desenvolvimento tecnológico, econômico e também pela segurança na Ásia.

Assim como Kissinger, Zbigniew Brzezinski também é tido como uma das mais proeminentes figuras intelectuais e políticas da Guerra Fria. Para a análise do referido tema, optou-se por discutir uma obra de sua autoria escrita durante a Guerra Fria, que analisa as mudanças tecnológicas daquele tempo e seus efeitos sobre as relações internacionais (Between two ages: america's role in the technetronic era, de 1970), assim como uma obra posterior, já do final do Século XX (The grand chessboard: america's primacy and its geoestrategic imperatives). Essa última foi escolhida, sobretudo, por tratar especificamente das implicações geopolíticas provenientes da grande massa continental eurasiana.

No livro Between two ages: america's role in the technetronic era, logo na introdução, Brzezinski (1970) afirma que o tempo e o espaço configuravam a percepção do mundo. Sendo assim, aquele momento histórico parecia obs- 
curecer a linha tênue entre política doméstica e internacional. No entanto, partindo de uma visão americana, tenta-se definir alguns entendimentos sobre os processos que ocorriam naquela ocasião, sem cair na dicotomia entre "bem" e "mau", tão comum ao ser humano.

Os países industrializados daquele momento, especialmente os EUA, pareciam estar em uma fase de transição, na qual a tecnologia e a eletrônica tinham cada vez mais importância nas mudanças sociais e políticas. $\mathrm{O}$ impacto da ciência e da tecnologia nos países mais avançados tem se tornado uma das principais fontes das mudanças do período. $\mathrm{O}$ autor ressalta ainda que enquanto a superpotência norte-americana figurava entre esses polos de avanço, a União Soviética ainda não havia entrado nesse cenário de transição tecnológica.

Brzezinski (1970) esclarece que a primeira globalização e americanização do mundo geraria confusões entre os diversos povos do mundo, inclusive entre aqueles da URSS, que poderiam acabar por concluir que sua realidade enquanto Estado Nacional não mais atendia às necessidades dos tempos. Ressalta ainda que o marxismo, enquanto institucionalização burocrática soviética não teria mais apelo, já que o leninismo nada foi além de uma russificação da teoria socioeconômica de Marx.

O mesmo autor assinala que, no pós-Primeira Guerra Mundial, dificilmente a Rússia cairia vítima da estagnação, dado que um país com sua extensão territorial, localização geográfica, vitalidade e herança imperial, independente do regime, indubitavelmente se desenvolveria. A isso ele adiciona que, nessas condições, a URSS se levantaria a um nível somente atingido por outro poder continental, os EUA. Continuando em seu argumento, ele postula que, apesar dos primeiros impulsos revolucionários da tomada de poder por parte dos bolcheviques, Stalin teria consumado o casamento entre o Marxismo-Leninismo e o Nacionalismo russo e que, num curto período de tempo, a elite bolchevique transitou de ser cosmopolita para ser dominada quase que inteiramente por russos étnicos e que a população, como em tempos anteriores, desenvolveu uma lealdade institucional e não intelectual ao regime. Sendo assim, a elite soviética, por mais que se pensasse internacionalista e revolucionária era, na verdade, conservadora e nacionalista.

Brzezinski (1970) argumenta que os chamados "valores eternos" da liberdade individual, democracia, liberdade, dignidade individual, etc., eram taxados de "ferramentas da burguesia para enganar as massas". Sendo assim, a elite soviética desconsiderava a teoria de política internacional da convergência entre as duas superpotências e acreditava serem as questões levantadas pelo Ocidente como dilemas não existentes no mundo soviético. 
Finalmente, Brzezisnki (1970) argumenta que as relações entre EUA e URSS não teriam previsão de melhora e, mesmo que se elas se tornassem menos ideologizadas, poderiam tornar-se mais extensas geograficamente. Ele diz ainda que a democratização da potência socialista provavelmente não traria o fim do embate entre ambos os polos, já que a rivalidade entre os países era inerente ao sistema internacional, fruto de séculos de competição e crença na superioridade de seus sistemas de valores. Mas, por outro lado, a democratização poderia tornar a URSS ainda mais forte, dado que seria descartado o modelo de estagnação então presente naquele país.

No entanto, como o sistema soviético não era mais atrativo e o avanço tecnológico ocidental era também muito superior, o mesmo autor diz que seria quase inevitável que o Leste Europeu gravitasse para a integração com o resto da Europa, dando as costas à URSS. Os EUA, por sua vez, deveriam modernizar sua doutrina diplomática e transitar do modelo clássico e militarista, até então usado, para um modelo de atração global e comunicação intensiva, deveria se usar do poder da televisão e dos computadores, na sua prática internacional. Para a URSS, o único modo de manter seu status seria aceitar a posição dos países da Europa Oriental e tentar, ela mesma, cooperar com os americanos.

Por outro lado, o livro The grand chessboard: america's primacy and its geoestrategic imperatives, escrito depois do fim da Guerra Fria, fornece apenas uma ideia geral do pensamento de Brzezinski acerca do papel do continente eurasiano na política internacional, o que muitos autores chamam de The Big Game. A Eurásia seria, então, o próprio tabuleiro sobre o qual esse jogo é jogado pelos diversos adversários.

O autor inicia sua análise dizendo que, durante os últimos 500 anos, os povos da Eurásia têm sido o centro do poder mundial. Apesar da hegemonia ter se instalado fora da Eurásia, para que os EUA mantivessem esse status, seria necessário impedir a emergência de uma grande potência eurasiana. Para reforçar seu argumento, Brzezinski (1997) percebia a Eurásia como o Tabuleiro de Xadrez Global, sobre o qual os destinos do mundo são decididos. Durante a Segunda Guerra Mundial, Stalin e Hitler concordaram entre si que os EUA deveriam ser excluídos da massa continental eurasiana e cada um deles acreditava que quem controlasse a Eurásia controlaria o mundo.

De um ponto de vista norte-americano, o mesmo autor afirma que se tornara necessário aos EUA expandirem sua esfera de interesse geopolítico ao fim da Primeira Guerra Mundial, já que haviam se tornado a maior economia do mundo e fonte de grande evolução tecnológica e ideológica. Brzezisnki (1997) prossegue sua análise argumentando que a era da política centrada na Europa havia terminado com o fim da Segunda Grande 
Guerra, que teria sido a primeira realmente global, lutada em três continentes e dois oceanos (Pacífico e Atlântico). A Eurásia teria, desse modo, se tornado um único campo de batalha.

Foram duas potências extraeuropeias (EUA e URSS) que assumiram o papel de detentores da supremacia global e que assim continuaram por 50 anos. Cada um dos lados propunha uma ideologia otimista acerca do futuro mundial, o que justificava o conflito e garantia a vitória final para algum deles. EUA e URSS teriam domínio indiscutível em suas respectivas esferas, mas nenhum deles chegara a dominar definitivamente a Europa.

A combinação entre geopolítica e universalismo das ideologias teria dado ao embate uma intensidade nunca antes vista. Apesar disso, o advento do poderio nuclear, a possibilidade da destruição mútua, com sérias consequências para grande parte da humanidade, teria feito com que ambos agissem de modo extremamente cauteloso.

De acordo com Brzezinski (1997), no âmbito geopolítico, o conflito se dera nas periferias da própria Eurásia. Enquanto a coalizão sino-russa dominava o interior do território eurasiano, os EUA entrincheiraram-se no extremo oriente e extremo ocidente da grande massa continental, sendo o bloqueio de Berlim e a guerra na península coreana os primeiros cenários dessa disputa. Nas últimas fases da Guerra Fria, surgira também um front austral na disputa. A potência capitalista norte-americana apoiava os rebeldes antissoviéticos no Afeganistão e posicionava grande poderio militar no Golfo Pérsico.

O sucesso da contenção dos EUA contra o bloco eurasiano se dera, finalmente, por meios não militares, devido ao medo da Destruição Mútua Assegurada. As dimensões essenciais dessa vitória foram a vitalidade política, a flexibilidade ideológica, o dinamismo econômico e o apelo cultural do bloco Ocidental. Além disso, havia o entendimento de que os aliados americanos eram significativamente mais fracos, enquanto que a China não aceitava ser tratada como subordinada à URSS. O resultado, por fim, se deu pela incapacidade da economia e tecnologia soviética em acompanharem os avanços americanos.

Sendo assim, o golpe final teria se dado com a recuperação econômica da Alemanha e do Japão, ao mesmo tempo que se atraiam crescentemente pelo modelo americano. Do outro lado, o domínio soviético significava para os povos do Leste Europeu isolamento daquele mundo que eles consideravam seu lar filosófico e cultural: a Europa Ocidental e a Civilização Cristã. Havia também nas nações da Europa Oriental um sentimento de serem subjugadas pelos russos, que consideravam como um povo culturalmente inferior. Para além desse cenário na Europa, na China também reascendia a chama antirrussa, considerando o povo eurasiático ao norte como bárbaro 
e um rival histórico. Dentro da própria União Soviética iniciaram-se os movimentos nacionalistas de contestação ao domínio russo.

\section{AS SEMELHANÇAS ENTRE AS TEORIAS DE GEOPOLÍTICA E A POLÍTICA EXTERNA DOS ESTADOS UNIDOS DURANTE A GUERRA FRIA}

Como forma de analisar as possíveis semelhanças ou diferenças entre as Teorias de Geopolítica e a Política Externa dos EUA, propõe-se analisar os argumentos principais de cada um dos documentos de política externa, buscando os pontos-chave comuns a todos eles. Sendo assim, os pontos-chave delimitados nos documentos da política externa norte-americana, aqui estudados, serão confrontados com as referidas teorias de geopolítica.

Neste sentido, afirma-se que os principais pontos comuns desses documentos são: a defesa dos valores da democracia e liberdade do indivíduo contra o totalitarismo da URSS e sua estratégia de dominação do continente eurasiano; o auxílio dos EUA ao desenvolvimento militar, econômico e moral do mundo livre; a insuficiência da vitória militar; a necessidade de reeducar os povos segundo os valores ocidentais, para que a União Soviética não se expandisse; o fortalecimento da Europa Ocidental, especialmente Reino Unido e Alemanha, já que, se o país germânico se tornasse neutro ou aliado da URSS, essa teria predominância na Europa, produzindo uma grande catástrofe para a segurança nacional norte-americana.

No que se refere aos possíveis paralelos entre esses tais pontos e as teorias geopolíticas previamente revisadas, pode-se mencionar a primeira e impressionante coincidência percebida na descrição da teoria mahaniana, ao conceber que tanto os EUA quanto o Reino Unido sentiam a ameaça das "hordas bárbaras" provindas da Ásia Central e do Norte, que poderiam se jogar contra a "civilização", tanto na Europa quanto no Pacífico.

Outro ponto de convergência entre o supracitado documento e a teoria de Mahan é o fato de que ambos postulam ser necessário defender os valores individuais, da democracia e da liberdade por meio do uso da força e que, se é verdade que as leis e instituições internacionais servem para esse propósito, também é verdadeiro que elas devem ser defendidas pelo fortalecimento do poder militar e pelo aumento do intercâmbio comercial entre as nações. Finalmente, quando os documentos postulam a impossibilidade do isolamento americano ao Hemisfério Ocidental (Mahan, 1897).

Ao fazer um paralelo entre a política externa norte-americana e a teoria geopolítica de Halford Mackinder, pode-se afirmar que a característica básica da teoria mackinderiana, a do heartland e seu cerco pelas potências marítimas, parece fazer eco na estratégia delineada nos documentos analisados quando se percebe o fortalecimento econômico e militar dos 
países da Europa Ocidental e da Ásia, sobretudo Japão e Grã-Bretanha. Além disso, da mesma forma que Mackinder (1904) afirmava ser uma aliança entre Rússia e Alemanha a maior ameaça para a potência marítima (naquele momento o Reino Unido). Ademais os documentos de segurança nacional confirmavam ser essa mesma aliança uma grande catástrofe para os Estados Unidos e seus interesses. Outro fator importante, que parece se fazer presente em todo o estudo, é a ideia de civilização versus barbárie ou "nossos valores de liberdade" versus "os valores deles de escravidão".

Quando feita a análise geopolítica de Isaiah Bowman ao fim da Primeira Guerra Mundial, o primeiro ponto que chama a atenção é a ressalva quanto aos problemas trazidos pelos bolcheviques russos e o movimento revolucionário internacional, além das tensões étnicas originadas pelo imperialismo russo. O combate ao "perigo revolucionário internacional” é delineado em todos os documentos, que o descrevem como uma herança desse imperialismo. Outro ponto comum entre a teoria bowmaniana e os documentos analisados é a preocupação na reeducação dos povos segundo os valores anglo-ocidentais, para que o poderio técnico dos povos do Ocidente não caíssem nas mãos de povos forasteiros, que buscassem destruir o "mundo livre" material e espiritualmente.

Bowman (1921) se refere à preocupação britânica de que a Rússia anexasse mais países europeus após a Guerra, enquanto que na Ásia, surgia uma lide entre Japão e Rússia sobre o controle da Ásia Central. É possível ver nessa situação uma semelhança com a estratégia oferecida nos documentos de apoio material e bélico à Europa Ocidental e ao Japão para impedir a expansão soviética.

Quando o foco recai sobre a obra de Nicholas Spykman, o primeiro ponto a ser destacado é o fato do autor tratar uma possível vitória do Eixo sobre os Aliados como uma "Aliança Eurasiana", que cercaria a Inglaterra e o "Hemisfério Ocidental", objetivando destruir a democracia. Apesar de não tratar, nesse primeiro momento, da URSS, o autor afirma, no fim de sua obra, que caso a potência socialista assumisse a estratégia alemã, todos os seus postulados teriam vigência também em uma luta contra a URSS. Sendo assim, se evidencia que a estratégia defendida pelos decision makers e intelectuais norte-americanos de fortalecimento da Europa e da Ásia contra a URSS, além da impossibilidade de isolamento hemisférico, é semelhante àquela descrita por Spykman (1938).

Para este autor, seria necessária uma Grã-Bretanha forte para que se mantivesse a necessária animosidade entre Alemanha e Rússia, cenário interessante para as pretensões americanas. No mesmo patamar que a aliança anglo-americana, Spykman (2007) coloca a aliança nipo-americana, ambas 
necessárias para a estratégia estadunidense na Eurásia. Uma vez mais é possível perceber as claras similitudes entre esse discurso e as políticas sugeridas nos documentos aqui analisados.

Apesar de haver diferenças pontuais entre os documentos de política externa, exemplificado na ligeiramente diferente forma de contenção sugerida por Kissinger (2011) em face daquela exposta no NSC 68, não se pode notar nenhuma discrepância essencial nos documentos daquele período. Da mesma forma, também não se percebe nenhuma mudança radical entre as teorizações geopolíticas, mesmo as mais antigas, como as de Mahan (1897) e Mackinder (1904), e a condução da política externa norte-americana durante o período da Guerra Fria.

\section{ANÁLISE DAS SEMELHANÇAS À LUZ DO “NEO-EURASIANISMO”}

Segundo Clover (2016), em um artigo para a revista Foreign Affairs, o Neo-Eurasianismo é o substrato essencial das ações russas na Geórgia, Ucrânia e Síria ao longo da última década, tanto devido à sua aceitação pela elite política daquele país, quanto pelo seu uso como teoria geopolítica na formação de Oficiais das Forças Armadas. Além disso, Klump (2011), em uma análise para o Wilson Center, afirma que o estudo do Neo-Eurasianismo não é interessante apenas para compreender a política externa russa, mas também a dinâmica interna daquele país e a influência que essa teoria desfruta em outros movimentos antiocidentais ao redor do mundo.

É essencial, para que iniciemos nossa análise, entender o caráter não apenas cientificista dessa teoria, mas também sociológico e teológico (Johnson 2014). A teoria do Neo-Eurasianismo se baseia, sobretudo, na geopolítica de Mackinder e Haushofer; na análise sociológica de Samuel Huntington e seu "Choque de Civilizações" e na teologia da história de Carl Schmitt. Além disso, bebe também da fonte dos Eurasianistas clássicos (Trubestkoy, Savitsky, Vernadsky, Alekseev, etc.) e da antropologia cultural (Franz Boas, Malinowski, Lévi-Strauss, etc.) (Dugin, 2012).

Do ponto de vista geopolítico, Alexander Dugin, o principal teórico do Neo-Eurasianismo, aceita os pressupostos mackinderianos básicos de que a história do mundo gira em torno do heartland eurasiático e das potencialidades globais para quem o controle. Além disso, ele acolhe em sua teoria a hipótese de que uma aliança entre Alemanha e Rússia tornaria a massa Eurasiática uma potência global capaz de superar quaisquer potências marítimas. De Haushofer, ele aceita a ideia de Autarquia e também incorpora em sua teoria o conceito de "Pan-Regiões", aprimorando-o com o conceito schmittiano de Grossraum (Grande Espaço), que divide o mundo em esferas de influência das grandes potências (Dugin, 2012). 
A ideia de "Choque de Civilizações", de Samuel Huntington, é incorporada à teoria duguinista juntamente com os estudos de antropologia cultural dos já mencionados autores. Sendo assim, ele propõe que não apenas os conflitos do pós-Guerra Fria serão entre diferentes civilizações e visões de mundo, como também que esses conflitos serão de civilizações particulares que ainda se encontram em algum grau do que se tem por "sociedade tradicional”, lutando contra a globalização e os ideais do ocidente liberal moderno. Sendo assim, ele postula que há uma espécie de resistência dessas sociedades a se adequarem ao modelo ocidental devido ao fato de que, como postula a antropologia cultural, não existe uma única forma de desenvolvimento humano, na qual o Ocidente moderno está à frente e os demais estão atrasados, mas diferentes modos de desenvolvimento e adaptação às novas realidades (Dugin, 2012).

O geopolitólogo russo também usa de elementos dos chamados "Eurasianistas", em sua teoria, que postulam ser a Rússia uma civilização própria, não inteiramente europeia e nem asiática, mas um meio termo entre elas, além de ter na religião ortodoxa a sua mais proeminente característica cultural. Da teologia da história de Carl Schmitt, ele inclui em sua teoria a tese de que a oposição geopolítica entre potências marítimas e potências terrestres não é apenas algo circunstancial e geográfico, mas também metafísico. Segundo essa teoria, a história universal é a luta entre esses dois polos elementares, representadas pelas bestas bíblicas, o Leviatã e o Behemoth. As potências marítimas, dos povos talassocráticos, seriam as representantes do Leviatã, enquanto que as potências terrestres e suas civilizações telurocráticas representariam o Behemoth e suas energias. Tais bestas, ou civilizações, assim como pensavam os cabalistas medievais, estariam em uma eterna luta de morte (Schmitt, 2007).

Dugin (2012) propõe que não apenas os conflitos do pós-Guerra Fria seriam entre diferentes civilizações e visões de mundo, como também que esses conflitos seriam de civilizações particulares, que ainda se encontravam em algum grau do que se entende por "sociedade tradicional”, lutando contra a globalização e os ideais do ocidente liberal moderno. Diante disto, postula-se que há uma espécie de resistência dessas sociedades a se adequarem ao modelo ocidental devido ao fato de que, como defende a antropologia cultural, não existe uma única forma de desenvolvimento humano, na qual o Ocidente moderno está à frente e os demais estão atrasados, mas diferentes modos de desenvolvimento e adaptação às novas realidades.

Diante do exposto, afirma-se que o Neo-Eurasianismo é a escola geopolítica russa que defende que a atual Federação Russa, assim como a antiga URSS e o Império Russo, são representantes do Heartland mackinderiano e, por isso, a mais forte potência terrestre existente, sendo o seu território 
e entorno imediato, o palco da luta global com a mais forte potência marítima atual, os EUA. Então, se de um lado a potência marítima representava os ideais ocidentais da liberdade individual, dos direitos humanos, da democracia liberal, etc., a potência terrestre teria representado sempre os valores do coletivismo, da tradição, da hierarquia, etc. (Dugin 2013).

Aliado a isso, a teoria Neo-Eurasiana apregoa que para desafiar o atual momento unipolar, no qual os EUA são o hegemon e atuam como ferramenta para a globalização liberal e a destruição de todas as sociedades não ocidentais, seria necessário que as diferentes civilizações se unissem em grandes blocos mais ou menos autárquicos, já que nenhum Estado Nacional isolado teria a capacidade de se contrapor ao hegemon.

No que diz respeito à geopolítica da URSS antes da Guerra Fria, no entendimento do Neo-Eurasianismo, deve-se destacar a contribuição do livro A geopolítica da Rússia contemporânea (2014), quando Dugin (2014) traça o perfil histórico da geopolítica russa desde o período czarista, passando pela União Soviética, até chegar à Rússia atual.

Nos argumentos deste autor, durante o governo do último Czar russo, Nicolau II, seu posicionamento geopolítico pessoal era a de aproximação com a França e com a Inglaterra, os quais ele afirma que, naquele período, eram representantes da talassocracia. Após o fim da monarquia, o poder do país ficara dividido em duas esferas: de um lado os deputados da Duma Estatal, que exerciam o poder provisório e, do outro os "Sovietes dos Deputados dos Trabalhadores e dos Soldados". Os primeiros mantinham uma posição geopolítica essencialmente igual àquela do Czar e os segundos, capitaneados pelos bolcheviques, postulavam uma postura pró-alemã e anti-inglesa/francesa.

Com o Tratado de Brest-Litovsk, de 1918, os bolcheviques aceitaram a independência de vários territórios, inclusive da Ucrânia, parte do Cáucaso, da Finlândia (entre outros), ao mesmo tempo que retiravam suas tropas dos países bálticos e concediam essa posição para os exércitos alemães. Segundo o autor, essa concessão teria sido feita pelos bolcheviques devido à sua inclinação em ter boas relações com os países da região, especialmente a Alemanha e por acreditarem na iminente revolução proletária no país germânico.

Sob este entendimento, a Guerra Civil irrompe com a tentativa de grupos de oposição aos bolcheviques tomarem o poder e reverterem o Tratado de Brest-Litovsk. Para Dugin (2014), há também nessa conflagração interna um "sentido geopolítico”, já que os bolcheviques (Vermelhos) representavam essa orientação para a Alemanha, a rejeição da "ordem burguesa” capitaneada pelos países liberal-democratas da Europa e, assim, uma rejeição à própria Entente. O chamado "Movimento Branco", por outro lado, não 
tinha um caráter ideológico homogêneo, como os Vermelhos. No entanto, o autor afirma que o que unia tanto a esquerda revolucionária antimarxista quanto os monarquistas e a direita burguesa era o entendimento de que deveria ser mantida uma linha de política externa pró-inglesa e pró-francesa.

Ao seguir o relato sobre as tendências geopolíticas das forças combatentes na Guerra Civil Russa, Dugin (2014, 30) ressalta dois cenários extremamente simbólicos e interessantes. O primeiro deles era o fato de que os bolcheviques controlavam "as zonas intra-continentais, o espaço do Heartland" e que as tropas do Movimento Branco se encontravam "ao longo da Periferia da Rússia” e "em redor das zonas costeiras", de onde elas receberiam apoio financeiro e militar das potências marítimas que as apoiavam. O segundo ponto por ele relatado é o fato de Sir Halford Mackinder ter sido apontado pela Coroa Britânica como "Alto Comissário Britânico para o Sul da Rússia” e enviado ao Leste Europeu. Nesse posto, ele recebeu a missão de apoiar as tropas anti-bolcheviques, envolver os governos anti-russos da Polônia, Bulgária e Romênia na contenda, além de tentar fazer com que os líderes do Movimento Branco aceitassem a criação de Estados independentes na Bielorrússia, Ucrânia, Yugo-Rússia, Daguestão, Armênia, Azerbaijão e Geórgia. Dugin (2014) afirma, então, que Mackinder "via nos bolcheviques as forças da Heartland, que estavam destinadas a adquirir uma forma ideológica comunista ou a ceder essa iniciativa à Alemanha” (31).

Uma vez passada a Guerra Civil, a reorganização do Estado teria começado de forma também revolucionária, mas logo retornado a métodos muito parecidos com o período czarista. Segundo o Dugin (2014), enquanto que num primeiro momento os bolcheviques não se mostravam preocupados com as demandas das minorias étnicas espalhadas pelo território, num segundo, o impulso centralizador tomou conta das estruturas de poder e logo foi concentrado quase que exclusivamente na Rússia. Da mesma forma, os ideais marxistas da revolução mundial e do internacionalismo teriam prevalecido no início da organização do Estado, tendo Lenin, Trotsky e inclusive Stalin concordado que a construção do socialismo num só Estado era apenas um passo insuficiente para a Revolução e que seria necessário colocá-la em marcha também em outros países. Da mesma forma que aconteceu com o poder central, também no quesito da política externa houve uma mudança brusca. Com a ascensão de Stalin, "a construção do socialismo num só país" torna-se num axioma da política soviética” (Dugin, 2014, 42).

Quando estourou a Segunda Guerra Mundial ("Grande Guerra Patriótica”, para os russos), houve duas tendências tanto dentro da URSS quanto da Alemanha Nazista. De um lado, os que postulavam por uma aliança entre as duas potências contra o Ocidente capitalista, e de outro 
os que postulavam a animosidade entre os dois países. Segundo o autor, na Alemanha os proponentes de tal estratégia iam desde os nacionalistas de esquerda ("Nacional-Bolcheviques"), passando pelos comunistas que restavam, até o geopolitólogo Karl Haushofer e seu círculo. Já na União Soviética, aderiam a esse ideia oficiais influentes das Forças Armadas dentro do GRU ("Glavnoye razvedyvatel'noye upravleniye" ou "Diretório Central de Inteligência”) e os círculos de intelectuais Eurasianos que restavam no país (Dugin, 2013).

A Aliança não teria ocorrido devido à preponderância dos setores antirrussos, racistas, antissemitas e anticomunistas na Alemanha (sendo também essa a visão pessoal de Hitler) e também pela megalomania do ditador alemão. Pelo lado soviético, o acordo teria sido dificultado pela crença pessoal de Stalin na teoria marxista e no internacionalismo, além da influência de esferas antialemãs em seu governo. Com esse cenário político e, tendo o Führer ordenado a invasão e destruição da URSS, o país comunista se viu numa situação em que seria necessária a aliança com as potências capitalistas. Segundo Dugin (2013), mais uma vez esse foi o pior cenário para as forças da "telurocracia”, já que os dois mais fortes Estados terrestres iriam destruir-se mutuamente e, em posição de vantagem, ficariam, novamente, as potências marítimas. A ocupação da metade da Europa e a repartição da Alemanha entre as potências capitalistas e a potência socialista teria sido, então, um meio de garantir o equilíbrio geopolítico global entre a "talassocracia" anglo-americana e a "telurocracia" soviética.

\section{CONCLUSÃO}

Com base nas análises feitas, ao longo deste trabalho, é possível concluir que existem semelhanças entre a política externa norte-americana, no período da Guerra Fria, e as teorias geopolíticas anglo-saxônicas, uma vez que os postulados geopolíticos são praticamente os mesmos da prática da política externa dos EUA para com a URSS, não havendo nenhuma mudança essencial entre os primeiros e os últimos.

Os documentos da política externa dos Estados Unidos, no período da Segunda Guerra Mundial até o final da Guerra Fria, adotam todas os postulados da teoria geopolítica Neo-Eurasiana (baseando seus escritos na distinção entre potências marítimas e terrestres).

Ainda, com base em Klump (2011), faz-se mister, nesse momento histórico que a academia brasileira e internacional se dedique a demorado estudo sobre o fenômeno do Neo-Eurasianismo enquanto base teórica da política externa e doméstica da Federação Russa, além de sua influência em movimentos antissistêmicos ao redor do globo. 
Finalmente, entende-se que se faz necessária uma exaustiva pesquisa acerca das causas da Guerra Fria, levando-se em conta não apenas uma comparação entre teorias de geopolítica e a política externa dos EUA, naquele período, como também um aprofundamento nas questões de caráter econômico, nas influências pessoais dos intelectuais e decision makers daquele governo, além de uma verificação das pressões internas nos EUA, tema sem o qual não é possível entender de maneira holista a política externa de um país e todas as suas peculiaridades.

\section{REFERÊNCIAS}

Albuquerque, E. S. 2010. A geopolítica da dependência como estratégia brasileira de inserção no Sistema Internacional. Oikos, 9 (1), 67-83. Disponível em: http:// www.revistaoikos.org/seer/index.php/oikos/article/view/179/128. Acessado em: 15 oct. 2016.

Bandeira, L. M. 2009. Geopolítica e política exterior Estados Unidos, Brasil e América do Sul. Brasília: Funag.

Bowman, I. 1921. The new world: problems in political geography. New York: World Book Company.

Brzezinsk, Z. 1970. Between two ages: america's role in technetronic era. New York: The Viking Press.

1997. Grand chessboard: american primacy and its geoestrategic imperatives. New York: Basic Books.

Clover, C. 2016. The unlikely origins of Russia's manifest destiny. Disponível em: http://foreignpolicy.com/2016/07/27/geopolitics-russia-mackinder-eurasia-heartland-dugin-ukraine-eurasianism-manifest-destiny-putin/?wp_login_redirect $=0$. Acessado em: 21 oct 2016.

Costa, W. M. 2010. Geografia política e geopolítica. 2. ed. São Paulo: Edusp.

Dugin, A. 2012. A geopolítica do mundo multipolar. Curitiba: Austral.

. 2013. The Great War of Continents. Retrieved July 12, 2016, from https:// openrevolt.info/2013/02/03/alexander-dugin-the-great-war-of-continents. 2014. A geopolítica da Rússia contemporânea. São Paulo: Versila.

Fukuyama, F. 1992. The End of History and the Last Man. New York: The Free Press. 
Kennan, G. 1947. The Sources of Soviet Conduct. Foreign Affairs, 26 (1), 1-10. Disponível em: https://www.foreignaffairs.com/articles/russian-federation/ 1947-07-01/sources-soviet-conduct. Acessado em 12 jul. 2016.

Johnson, M. R. 2014. Nationalism and eurasianism: the ideology of russian regional power and the rejection of western values. Disponível em: https://syncreticstudies.com/2014/08/02/russian-nationalism-and-eurasianism-the-ideology-of-russian-regional-power-and-the-rejection-of-western-values. Acessado em: 3 nov. 2016.

Kissinger, H. 2011. White House Years: 1968-1972. New York: Simon \& Schuster.

Klump, S. D. 2011. Russian eurasianism: an ideology of empire. Disponível em: https://www.wilsoncenter.org/publication/russian-eurasianism-ideology-empire. Acessado em: 3 nov. 2016

Mackinder, H. J. 1904. The geographical pivot of history. The Geographical Journal, 23 (4), 421-437.

Mahan, A. T. 1897. Interest of america in sea power: present and future. London: Sampson Low, Marston \& Company.

Schmitt, C. 2007. Tierra y Mar. Madrid: Trotta.

Spykman, N. J. 1938. Geography and foreign policy. american political science review, 32 (01), 28-50.

Spykman, N. J. 2007. America's strategy in world politics: the United States and the balance of power. New Brunswick: Transaction.

Wells, S. F. 1979. Sounding the Tocsin: NSC 68 and the soviet threat. International Security, 4 (2), 116-158. 


\section{NOTAS}

1. Desde os anos 1920, também no Brasil, surgiu o estudo de geopolítica em compasso com as ideias do mundo anglo-europeu. No entanto, ao contrário do que ocorria no Hemisfério Norte, sendo essa ciência estudada sobretudo por acadêmicos, no Brasil ela foi, majoritariamente, militar. Nos seus primórdios temos os trabalhos de Everardo Backheuser, posteriormente os estudos dos generais Mário Travassos e Golbery de Couto e Silva e, finalmente, na década de 1970 em diante, os estudos do também General Carlos de Meira Mattos, para citar alguns dos mais importantes (Costa, 2010). 


\section{NEO-EURASIANISMO, GEOPOLÍTICA E A POLÍTICA EXTERNA DOS EUA À URSS DURANTE A GUERRA FRIA}

\section{RESUMO}

Este artigo baseia-se na teoria geopolítica do Neo-Eurasianismo. Assim, considera-se que uma das causas da Guerra Fria tenha sido a oposição geopolítica entre os Estados Unidos (potência marítima) e a União Soviética (potência terrestre). Nessa direção, este estudo tem como objetivo analisar os padrões de comportamento entre as teorias geopolíticas e os documentos da política externa concreta dos EUA à URSS, desde o fim da Segunda Guerra Mundial até o fim da Guerra Fria. Em termos metodológicos, trata-se de uma pesquisa documental e bibliográfica. Conclui-se que existem semelhanças entre a política externa norte-americana, no período da Guerra Fria, e as teorias geopolíticas anglo-saxônicas, uma vez que os postulados geopolíticos são praticamente os mesmos da prática da política externa dos EUA para com a URSS, não havendo nenhuma mudança essencial entre o preconizado teoricamente e as práticas (documentais) adotadas.

Palavras-chave: Geopolítica; Guerra Fria; Estados Unidos; União Soviética; Neo-Eurasianismo.

\section{ABSTRACT}

Based on the geopolitical theory of Neo-Eurasianism, it is assumed that one of the causes of the Cold War was the geopolitical opposition between the United States-US (maritime power) and the Soviet Union-USSR (land power). In view of the above, the objective is to analyze the patterns of behavior between geopolitical theories and the US foreign policy documents for the USSR from the end of the Second World War to the end of the Cold War. In methodological terms, this is a documentary and bibliographical research. It is concluded that there are similarities between the US foreign policy in the Cold War period and Anglo-Saxon geopolitical theories, since the geopolitical postulates are practically the same as those of the US foreign policy practice towards the USSR, there being noessential change between the first and the last.

Keywords: Geopolitics; Cold War; United States; Soviet Union; Neo-Eurasianism 